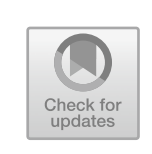

\title{
Twelve Principles of Quantum Leadership
}

We have seen that becoming a quantum leader requires becoming a good person. It requires being a person of integrity whom others can trust. But even more than that, it requires being a person whose own example can inspire others, someone whose life and being can show others the way, someone who in his or her life has walked the quantum path of self-cultivation and ever-renewed self-creation, who can rise to challenges, aspire to higher things, and bring out the best in others, turn others into leaders. Typically, a Western guide or self-help book on such leadership would offer a formula, a set of steps to take or rules to follow, in the spirit of the Bible's Ten Commandments. But formulae and rules are contrary to the very spirit of the quantum paradigm and a quantum organization. Each quantum person is unique, just as each quantum company is unique, and thus a guide for quantum leadership should offer a set of general principles that each leader can follow in a self-organizing and adaptive way.

But which principles should guide a quantum leader? The Chinese word for "leader" is "lingdao." "Ling" means "to know," and "dao," of course, is the Tao, the Way. The Chinese believe it is the role of leaders to know the Way of the cosmos and Nature and to bring that into the world of human activities. Today, many complexity scientists agree with them. Men like complexity economist Brian Arthur and physicist Geoffrey West believe that human social systems like companies and cities function optimally as complex adaptive systems, i.e., living quantum systems.

(C) The Author(s) 2022

D. Zohar, Zero Distance, https://doi.org/10.1007/978-981-16-7849-3_13 


\begin{tabular}{c|c|c}
\hline QUANTUM SYSTEMS & CAD'S & LEADERSHIP \\
\hline $\begin{array}{c}\text { Self-Organizing } \\
\text { Indeterminate } \\
\text { Emergent Led } \\
\text { Holistic }\end{array}$ & Self-Organizing & Self-Awareness \\
Bounded Instability & Spontaneity \\
Evolutionary & Vision \& Value \\
Holistic & Holism \\
Contextual & In Dialogue With Environment & Compassion \\
Wave Function "Collapse" & Adaptive & Celebration of Diversity \\
Heisenberg Uncertainty & Outside Control Destructive & Field Independent \\
Principle & Exploratory & Ask Why? Questions \\
Create New Realities & Recontextualize Environment & Reframe \\
Participatory Universe & Every Element of System & Humility \\
Negative \& Positive Cosmic & Important & Positive Use Adversity \\
Forces & Order Our of Chaos & Sense of Vocation \\
\hline
\end{tabular}

Fig. 13.1 Quantum systems, CAD's, and quantum leadership principles

That is also, of course, the argument of this book. Therefore quantum leaders should be guided by the same principles that define these systems. Thus, the twelve quantum leadership principles described just below are the conscious equivalents of the twelve defining qualities of quantum systems and complex adaptive systems. This correspondence is illustrated in Fig. 13.1.

\section{The Twelve Leadership Principles Are}

- Self-Awareness-Socrates said, "Know thyself." The principle of self-awareness is knowing who I am, what I believe in, what I value, and what motivates me. Knowing my strengths and weaknesses, both as a person and as a leader. Knowing how I affect others. How do others see me? Knowing my life's purpose and how that aligns with my purpose as a leader. Am I in touch with my inner compass and led by its sense of direction? Am I even aware that I have an inner compass, a deeper self beyond my ego and its daily concerns? 
The principle of self-awareness relates to the fact that complex adaptive systems are self-organizing, and that quantum systems spontaneously reorganize as their environments change.

- Vision \& Value Led-Acting from principles, deep beliefs, and living accordingly. Reflecting on our values and remaining true to them. Aspiring to make a difference, to make "the world a better place." Idealistic. Longing for "the not yet born." Positively motivated. Inspired and inspirational. Having a vision for ourselves or our companies is not just having a "goal" or a "target." It is about assigning a meaning to our lives or to our company, having a purpose, knowing what our lives or our companies are about.

The principle of being vision and value led relates to the fact that complex adaptive systems are driven by the "purpose" of both sustaining themselves and experiencing evolutionary growth. They are emergent, creative. Quantum relationships are emergent, furthering the natural direction of the universe toward creating ever more complexity, order, and information.

- Spontaneity-To be an authentic person or to lead an agile company, a person must have the capacity for spontaneous response. The principle of spontaneity calls upon us to live in and be responsive to the moment. Being able to see what this moment or this situation calls for and being flexible enough to adapt my decisions and actions accordingly. Not looking to the past for solutions or understanding, but responding to this situation or person now. Dropping the "baggage" of assumptions and conditioned thinking, the baggage of past "wisdom" and success, the baggage of past grievances or failures, the baggage of theory and ideology. Seeing the world through the eyes of a child. Spontaneity is not the same as acting on whim or impulse. These involve no thinking at all. By contrast, spontaneity is a feature of adaptive thinking.

Principle of spontaneity correlates with bounded instability of complex adaptive systems. These systems exist only at the edge of chaos, in a zone of radical instability, and thus maintain the flexibility necessary to respond and adapt spontaneously and creatively to changes in their environment. Quantum indeterminism allows the same flexibility for the evolution of quantum systems.

- Holistic-This principle means an ability to see larger patterns, relationships, and connections between things. Being sensitive to the 
relations at play in a situation, and building good quality relationships. Sense of belonging to the whole, of seeing yourself and your company as systems and as part of a larger system. Knowing that everything is connected to everything and that you are connected to everything and to everyone. Realizing there is no such thing as separation, and acting accordingly. Knowing that everything you do, every decision you make, has consequences-for yourself and for others. Seeing that every question has at least two sides, and that there is an underlying wholeness within the differences. Ability to see the infinite within the finite, and able to see deeper currents or patterns within events and situations.

The principle of holism relates to the fact that complex adaptive systems are holistic. Every part is related to and dependent upon every other part. There are no internal boundaries, no recognizably separate parts. The same is true of quantum systems.

- Field-Independent-This principle means having an ability to stand against the crowd and follow our own convictions. To have the strength and the courage to do what we think is right even if "everyone" is telling us it is wrong. To have the resilience to be unpopular, to not bend if we are mocked or excluded. To stay true to our principles in the face of temptation or criticism. And yet always to be self-critical, to be on guard against our own hubris and the traps and tricks of our own thinking. This protects us from fanaticism and gives us a reality check.

Field independence relates to the fact that the creativity of complex adaptive systems is destroyed by outside control. These systems, if controlled from outside, lose their self-organization and revert to being simple Newtonian systems. Field independence also correlates with fact that measurement or observation "collapses" the quantum wave function.

- Humility: The wise leader is always alert to the ignorance in his own mind and the wickedness in his own heart. On this earth, there is no such thing as a Perfect Man, and thus no such thing as a perfect leader. The humility of the quantum leader reminds him/her constantly of this. Confucius realized this when he said: "I question myself three times a day." Humility requires a sense of being a player in a larger drama and of our true place in the world. Growing beyond arrogance and self-assertion. Realizing that others know things, too, and that no one person can ever know it 
all. Knowing when we are out of our depth and being willing to seek help or advice. Knowing that even I can make mistakes or be wrong. Being willing to acknowledge and respect the expertise of others. Being willing to trust others. Not always having to be the best, not always having to be the boss.

The principle of humility relates to property of complex adaptive systems that every element of the system is important and necessary, and each element depends on all. It also relates to fact that the quantum universe is a participatory universe.

- Ability to Reframe-Standing back from a situation or a problem and seeing the bigger picture; seeing problems and opportunities in a wider, or new, context; changing one's mindset. When we stand back from a problem, or from a decision that we have made, we gain the benefit of seeing our own behavior and thinking as though we were a neutral, third person, someone observing ourselves from a distance. We become our own coach or consultant. From this objective vantage point, we become aware of assumptions or habits that underpinned the thinking or the decision, and thus become better masters of both ourselves and of that situation or problem. We can then ask ourselves creative questions like, "How would this look differently to me if I surrendered that assumption? How would this situation be different if I acted this way instead of that? What if...?" Our minds begin to churn out new ideas, new questions, new possibilities. We begin to change the way we frame things, and then we find ourselves becoming new actors in new situations, now approaching things differently and able to make fresh, and quite possibly better, decisions. In a moment, I will outline a reflective process that helps us develop the skill of reframing.

Principle of reframing corresponds to fact that complex adaptive systems recontextualize their environment, and quantum systems develop new, emergent properties through relationship.

- Ask Fundamental "Why" Questions-A need to understand things, to get to the bottom of them. Wanting to know how things work, why things happen, or why we are being asked to do something. Wanting to understand the logic behind events. Reluctant to take things for granted, instead questioning their reasons and foundations. Having a spirit of inquiry and a passion to learn. Being curious. Asking why myself and others behave as we do. Questioning my own and others' assumptions. Having the courage to rock the 
boat, even our own. Always wanting to go deeper into any question. Asking if things could be different or better. Valuing good questions over necessarily finite and short-term answers. Reflecting on life's "big questions."

Principle of asking fundamental questions corresponds to fact that complex adaptive systems are exploratory, and that quantum potentiality is transformed into reality by doing experiments and asking questions.

- Celebration of Diversity-Exposing ourselves to things, experiences, ideas, examples that are different. Seeking out and opening ourselves to others' points of view, to ideas and opinions that challenge or broaden our thinking. Recognizing that broadening our knowledge and experience is crucial to developing an appreciation for and understanding of others. Recognizing that truth is multifaceted, perhaps infinite, and thus in many circumstances there is no "one best way." Able to respect and even benefit from points of view that are different than our own. Going outside our own comfort zone to gradually extend its boundaries. Able to challenge our own assumptions and preferences. Appreciating others for their differences rather than despite them.

Celebration of diversity corresponds with a complex adaptive system's reliance on evolutionary mutations for transformation. Mutations play a creative role in the newly emergent structure of these systems' future. Mutations, and the quality of mutability, play keys roles in the sustainability of life on earth. And quantum thinking allows us to hold two seemingly opposing beliefs or ideas and appreciate that, in many cases, both can be true. Quantum entities exist as both particles and waves at the same time, can be everywhere at the same time.

- Positive Use of Adversity-Sun Tzu's Art of War tells us, "Victory comes from finding opportunities in problems," 1 and it is now almost common knowledge that the Chinese word for "crisis" contains the two elements, "danger" and "opportunity." Positive use of adversity is the ability to learn from mistakes, grow and learn from setbacks and suffering, and to turn problems into opportunities. Becoming stronger and wiser from having been tested. Able to carry on even though we have a tragic recognition that not all

${ }^{1}$ Sun Tsu, Chapter 3, No. 5 . 
problems have solutions. Able to look at our own weaknesses and overcome them. Resilient. Stubborn!

Principle of Positive Use of Adversity correlates with complex adaptive systems' ability to bring order out of chaos. They have "negative entropy," bringing new order and form into situations where, before, there was none. In quantum physics, the positive, creative force of the universe defeats the negative, destructive force of entropy.

- Compassion-Quality of "feeling-with" and deep empathy. Able to experience what others may be feeling or going through, and concerned about their plight. Having a desire, where possible, to make their circumstances less burdensome or painful — for their sake. Knowing that we are all one, and thus I am them. We are not just our brother's keeper; we are our brother. Feeling this common human bond and thus some understanding even of those who are our enemies or by whom we feel threatened, thus making forgiveness possible. Showing others respect and taking care of their dignity. Treating others as we would like to be treated.

The principle of compassion resonates with the quality of complex adaptive systems BEING adaptive, in a co-creative dialogue with their environment. It also resonates with the contextual nature of quantum systems' being and identity.

- A Sense of Vocation: "Vocation" is derived from the Latin word vocare, "to be called." The first vocations were those of monks who dedicated their lives to serving God. Having a sense of vocation is to feel called upon to serve, to give something back, to leave the world a better place than you found it, or having a passion to bring something new into the world, a sense that this just has to be. And having found a way to act on this through our career or life's dedication. Thus having the feeling that our job or our life is our prayer, our contribution, or service. Feeling responsible to the world and for the world and taking that responsibility through our actions and commitments. Having a sense of vocation is much deeper than having an ambition or a goal. It is having a sense of purpose and direction in our lives, a sense of what we are here for, and of having found a path in life through which we can realize this. A sense of vocation is a definitive quality of the servant leader, and often of the entrepreneur. Let us ask ourselves: Do I feel I have a "calling," a life purpose? What is it? Am I able to live that purpose through my leadership? Or do I feel empty, dissatisfied, rudderless? Do I fill my 
life with ambitions, like getting rich or being successful? Am I just out for myself? Whom or what do I serve?

Having a sense of vocation resonates with the positive force in the universe driving the cosmos toward ever greater complexity, ever more order and information, and with the life force in complex adaptive systems that drives them both to sustain themselves and to evolve.

\section{Reflective Practice}

We will see that reflective thinking is one of the skills of quantum thinking. To gain the most benefit from knowing these twelve principles of quantum leadership, it is best to use them as a guide to daily reflective practice. This is a practice I developed for my own use, and I have found it an effective way both better to understand myself and to put the day's activities and interactions into a wider perspective. Without question, any kind of reflection increases both self and situational awareness, but focusing such reflection on one or other of the twelve principles helps us better to live and lead with that principle.

Reflective practice is best done at the end of the day. It must be done in a quiet place where one can be comfortable and free from distraction. Personally, I go into my sitting room, turn off the lights, and sit by fire and candlelight. Once comfortable, it is important to bring our attention to the body, noticing how it feels. Where is my body tense or uncomfortable? Is there a "lump" in my stomach? Is my breathing fast or slow? Do I have a headache or a stiff neck? Am I clenching my fists or fidgeting? Our bodies act as the wastebins of the mind. All of the stressful events of the day get lodged in them, blocking their natural energy flow.

Once we've become aware where our bodies are feeling discomfort, we begin to ask, "What?" What happened today that might have upset me? Was it an incident at work? An exchange with someone at home? Am I stuck on a problem? Do I just feel too much has come at me today? Did someone or something frustrate me? If the answer to any of these questions increases the tension in my body, it needs further inquiry. So I begin to ask, "Why?".

Why did that exchange I had today upset me? Why do I get upset about something like that? What is it about me that made me vulnerable in that situation? Was the situation caused by something I said or did? Why did I say or do it? Could I have handled it differently? Could I have 
avoided it? Why didn't I? Do I get into exchanges like this because of some habit or leaning in my personality? Why am I like this? Could I change? Why? Why? Why? Each act of asking "Why?" gets us deeper into the situation and deeper into the way that we think and act about people and situations. It surfaces assumptions and habits and attitudes of which we had previously been aware. It also gives us a broader perspective on others and on their problems.

The reflective process of plunging deeper into some disturbing incident of the day is not endless. Inevitably, the act of repeatedly asking "Why?" will generate an insight that causes the body to let out a deep sigh of relief, and the tension it had been holding dissolves. This will have positive consequences for blood pressure, clarity of thought, and quality of sleep. It can be thought of both as a daily house cleaning of the mind, and an act of daily, increased self-awareness-and self-mastery.

We human beings are a species that asks questions, especially questions of meaning. If we think back to the lessons of Heisenberg's Uncertainty Principle, it is the questions we ask that give us the answers we get. The questions we ask tease out the potentialities of quantum reality and also the potentialities of our own minds and being. The questions we ask create the world we live in. And, most definitely, they create the person that each of us is. By examining ourselves with a series of probing Why? questions at the end of each day, we mine the hidden lessons and potentialities of the day and perform regular, small acts of self-creation. Becoming a better self makes each of us a better leader.

In the quantum organization, where all employees are leaders, these same twelve principles must underpin the organizational culture, thus encouraging all to live them. 
Open Access This chapter is licensed under the terms of the Creative Commons Attribution-NonCommercial-NoDerivatives 4.0 International License (http:// creativecommons.org/licenses/by-nc-nd/4.0/), which permits any noncommercial use, sharing, distribution and reproduction in any medium or format, as long as you give appropriate credit to the original author(s) and the source, provide a link to the Creative Commons license and indicate if you modified the licensed material. You do not have permission under this license to share adapted material derived from this chapter or parts of it.

The images or other third party material in this chapter are included in the chapter's Creative Commons license, unless indicated otherwise in a credit line to the material. If material is not included in the chapter's Creative Commons license and your intended use is not permitted by statutory regulation or exceeds the permitted use, you will need to obtain permission directly from the copyright holder.

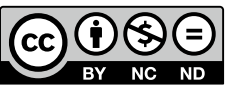

